\title{
NOTA
}

\section{DESCRIPCIÓN DEL DESARROLLO LARVARIO POST- ECLOSIÓN DE Australoheros facetus Jenyns, 1842 (OSTEICHTYES, PERCIFORMES, CICHLIDAE) EN LABORATORIO.}

\author{
Daniel Carnevia \\ Área Acuicultura y Patología de Organismos Acuáticos, Instituto de Investigaciones Pesqueras, Facultad de \\ Veterinaria, Tomás Basañez 1160, Montevideo 11300, Uruguay. \\ dcarnevia@gmail.com
}

\section{RESUMEN}

El presente trabajo comprende la descripción macroscópica del desarrollo larvario post-eclosión de Australoheros facetus. La fase protolarva se define desde la eclosión a las 160 horas; la fase mesolarva desde las 160 a las 500 horas; la fase metalarva desde las 500 a las 1000 horas, iniciándose entonces la fase de alevino o prejuvenil.

Palabras Clave: Cichlidae, Australoheros facetus, desarrollo larvario.

\section{ABSTRACT}

Description of the post hatching larval development of Australoheros facetus Jenyns, 1842 (Osteichtyes, Perciformes, Cichlidae) in laboratory. The present work includes the macroscopic description of the post - hatching development of Australoheros facetus. The protolarva phase occurs from hatch to 160 hours, the mesolarva phase from 160 to 500 hours, the metalarva phase from 500 to 1000 hours, when the phase of fry or alevin is starting.

Keywords: Cichlidae, Australoheros facetus larval development.

El pez Australoheros facetus Jenyns, 1842, llamado vulgarmente "castañeta" o "chanchita" es un cíclido que se distribuye en todo el territorio nacional, así como en el centro y norte de Argentina y sur de Brasil. Es una especie omnívora, que alcanza un largo máximo de $25 \mathrm{~cm}$ y habita ríos, arroyos y lagunas en lugares con abundante vegetación (Teixeira de Mello et al., 2011). Este pez es de fácil reproducción en cautiverio, tiene buena prolificidad (200 a 800 crías por desove) y una relativamente fácil larvicultura y crecimiento por lo que se puede utilizar como pez de laboratorio y como pez ornamental. En el bioterio del Instituto de Investigaciones Pesqueras, se desarrolla la producción y crecimiento de ejemplares para luego utilizarlos en diversos proyectos relacionados con la patología, el cultivo y la toxicología. En este contexto el presente trabajo comprende la descripción macroscópica del desarrollo larvario posteclosión de $A$. facetus, que además de un aporte al conocimiento de la biología de la especie, servirá como referencia para el monitoreo del grado de desarrollo de las larvas y para la planificación de manejos específicos durante la larvicultura en laboratorio. También por tratarse de una especie invasora en Chile, Portugal y España, la descripción de formas larvarias puede servir para estudios en dichas localidades (Arratia, 1978, Ribeiro et al., 2007).

Para la realización de este trabajo se utilizaron cinco desoves obtenidos en laboratorio, los que se mantuvieron entre 25 y $28{ }^{\circ} \mathrm{C}$. El número de peces por desove varió entre 142 y 1012. Una vez eclosionadas las larvas se procedió a colectar ejemplares a las $6,12,24,48,100,160,300,500$, 750 y 1000 horas. Estas larvas fueron observadas vivas en fresco al microscopio fotónico con 40 y 100 aumentos, para ser fotografiadas, medidas y dibujadas. Las estructuras y estadíos identificados se basaron en las descripciones realizadas por Cabrera et al. (1988), Meijide \& Guerrero (2000) y Molina (2011), las que fueron comparadas con la especie en estudio en el presente trabajo.

\section{Fase protolarva (Figura 1)}

a. Estadio post eclosión (de 0 a 24 hs): miden 5,12 a $5,52 \mathrm{~mm}$. Sin boca, gran vesícula vitelina, melanóforos localizados en la región ventral. Plexo respiratorio embrionario desarrollado. Tres pares de glándulas adhesivas en cabeza no funcionales.

b. Estadio saco vitelino (24 a 100 hs): 5,52 a 5,75 $\mathrm{mm}$. Aparecen las mandíbulas y los primordios de los arcos faríngeos. El extremo caudal del notocordio se flexiona dorsalmente. Aparecen las aletas pectorales. Las glándulas adhesivas son muy funcionales lo que les permite fijarse a un sustrato y moverse provocando la circulación de agua.

c. Estadio boca abierta (100 a 160 hs): 5,75 a $6,30 \mathrm{~mm}$. La boca está abierta y es móvil. Hay esbozos de arcos branquiales. Se observan 


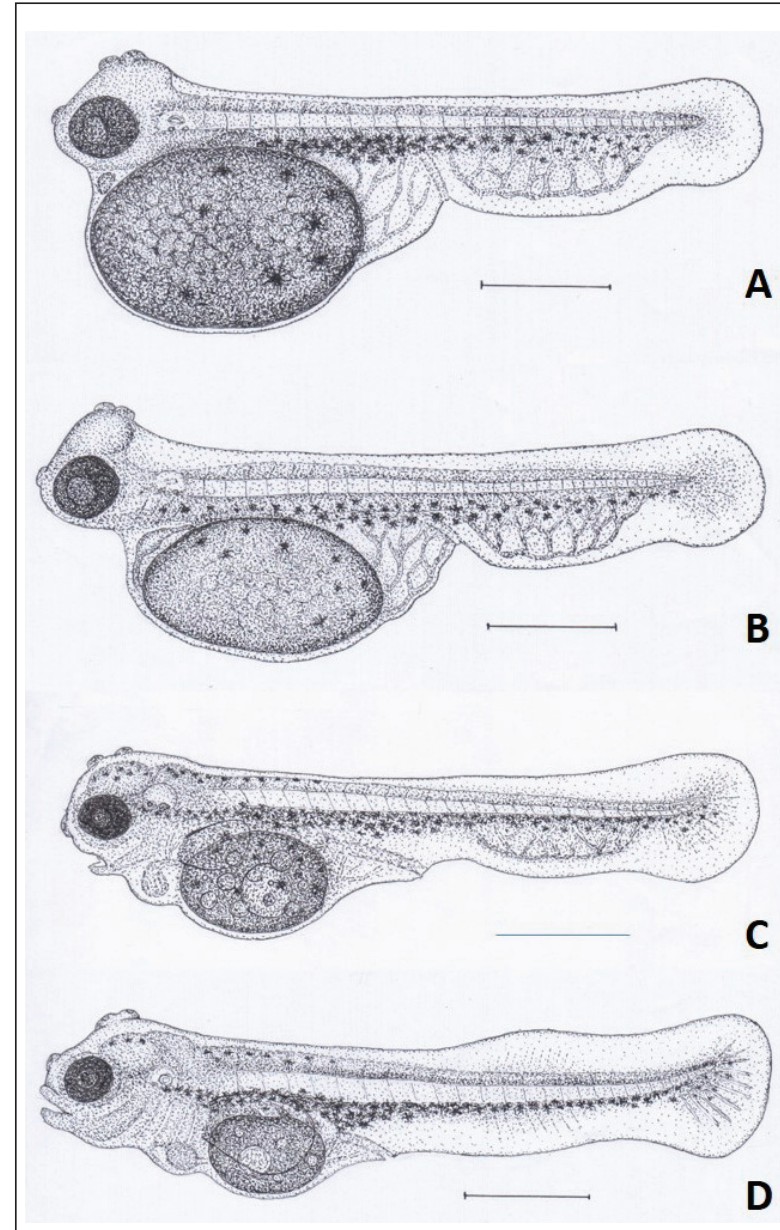

Fig. 1. primordios de radios en el pliegue de aleta caudal. Aparecen melanóforos en la cabeza y parte anterior del tronco.

\section{Fase mesolarva (Figura 2)}

a. Estadio nado libre (160 a 300 hs): 6,30 a 7,4 $\mathrm{mm}$. Se observan dientes en la boca. Se puede apreciar el opérculo cubriendo branquias ya desarrolladas. Las glándulas adhesivas han desaparecido y se observa la vesícula gaseosa y el nado en cardumen. Se observan primordios de radios en pliegues de aletas dorsal y anal. Radios en aleta caudal desarrollados pero sin segmentar. Se pierde el plexo respiratorio embrionario. Comienza la alimentación exógena.

b. Estadio aletas impares (300 a $500 \mathrm{hs}$ ): 7,4 a 8,5 $\mathrm{mm}$. Vitelo totalmente consumido. Radios de aletas dorsal y anal ya formados. Comienza el desarrollo de las aletas pélvicas. Patrón de pigmentación a lo largo del cuerpo, manchas en posición dorsal y ventral en nacimiento de la cola. Radios de la aleta caudal con

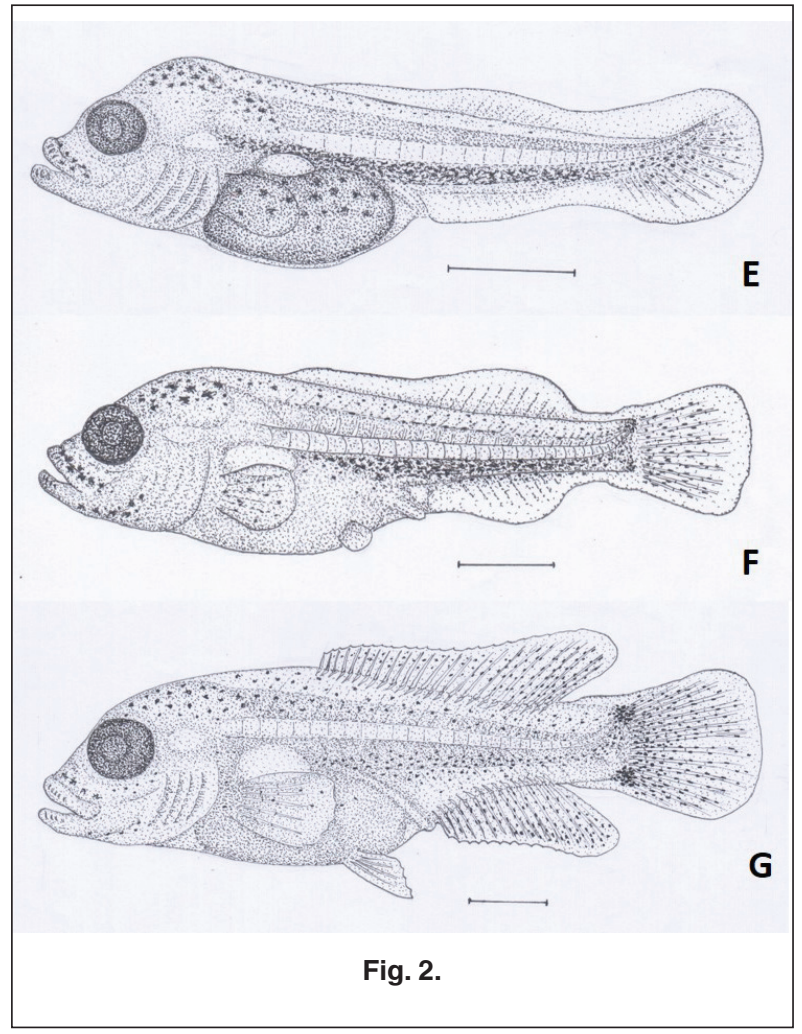

articulaciones. Aletas impares ligeramente pigmentadas.

\section{Fase metalarva (Figura $3 \mathrm{H}$ )}

Estadío aletas completas (500 a 1000 horas): 8,5 a $11 \mathrm{~mm}$. Completo desarrollo de aletas impares y pectorales. Pélvicas con radios desarrollados sin segmentar. Patrón de coloración que se asemeja a los juveniles con melanóforos y eritróforos. Comienzan a desarrollarse escamas en los lados del cuerpo.

\section{Fase alevino o prejuvenil (Figura 3l)}

Estadio Alevino (más de 1000 horas): 11 a 50 $\mathrm{mm}$. Aletas totalmente formadas. Escamas cubriendo todo el cuerpo. Narinas totalmente desarrolladas. Coloración similar al adulto en bandas verticales oscuras y claras.

El desarrollo de $A$. facetus es similar en cuanto a la duración de las etapas a Cichlasoma dimerus, que también presenta unas 1000 horas hasta alcanzar el desarrollo completo de las aletas, escamas y coloración similar al adulto (Cabrera et al., 1988). Por otro lado es más lento que el descrito para Cichlasoma dorii y Hypsophrys nicaraguensis 


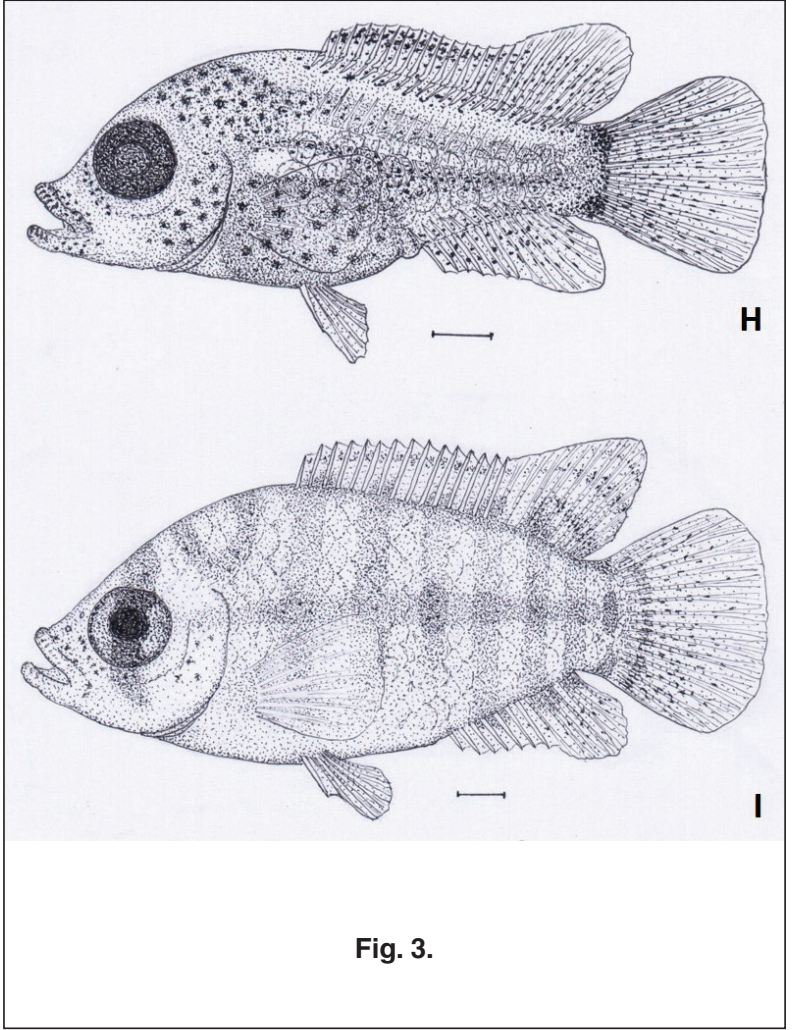

las cuales alcanzarían la etapa de alevino en 480 a 500 horas (Meijide \& Gerrerro, 2000; Molina, 2011).

En base a este trabajo, podemos planificar y mejorar algunos aspectos relativos a la acuicultura como la posibilidad de alimentar las larvas con nauplios de Artemia a partir de las 150 horas de vida, separar las mismas de los padres a las 500 horas y acceder a la siembra en estanques a partir de las 1000 horas.

\section{REFERENCIAS}

Arratia G. 1978 Comentario sobre la introducción de peces exóticos en aguas continentales de Chile. Ciencias Forestales, 1: 21-30.

Cabrera J., Murillo R. \& Mora M. 1988 Desarrollo embrionario, larval y del alevin de Cichlasoma dorii (Pisces: Cichlidae). Revista de Biología Tropical, 36: 417-422.

Meijide F. \& Guerrero G. 2000. Embryonic and larval development of a substrate-breeding cichlid Cichlasoma dimerus under laboratory conditions. Journal of Zoology, 252: 481-493.

Molina A. 2011. Larval development of Hypsophrys nicaraguensis (Pisces: Cichlidae) under laboratory conditions. Revista de Biología Tropical, 59: 1679-1684.

Ribeiro F., Orjuela R., Magalhaes M. \& Collares-Pereira M. 2007. Variability in feeding ecology of a South American cichlid: a reason for successful invation in mediterranean-type rivers? Ecology of Freshwater Fish, 16: 559-569.

Teixeira de Mello F., González-Bergonzoni I. \& Loureiro M. 2011. Peces de agua dulce del Uruguay. PPR-MGAP. 188 pp.

Fecha de Recepción: 12 de diciembre de 2016 Fecha de Aceptación: 21 de junio de 2017 